\title{
Comparison among Views of Teaching Departments' Heads Regarding their Role in Promotion of Communication in Universities of Khyber Pakhtunkhwa
}

\author{
Rahmatullah Shah ${ }^{1}$
}

\begin{abstract}
Study has investigated comparison among views of heads of teaching departments by; academic qualification, age, length of service and experience and chairperson regarding their role in promotion of communication in universities of Khyber Pakhtunkhwa. This study was descriptive in nature. Survey method design was used for the study. The population of the study consisted of all heads of teaching departments of public sector universities in Khyber Pakhtunkhwa, Pakistan. The researcher randomly selected eight universities out of 12 universities. A questionnaire consisted of 27 items was filled from 124 respondents. AVOVA was used as a statistical technique for data analysis. Results revealed no significant difference in the views of heads by qualification, age and total length of experience. However, significant difference was found among the views of heads by experience as chairperson.
\end{abstract}

Keywords: Communication, Heads, Teaching Departments, Promotion.

\section{Introduction}

Communication is vital for the management of every organization. These organizations range from a small home to a multinational company. Communication is an essential part of the management of an educational institution. Communication plays a key role in the management of a university. Teaching department is called an academic department. The head of teaching department is called chairperson. The chairperson manages the department. For effective management of the department sharing of information is necessary among stake holders. Managers of educational institutions spend a great of deal of time in communication. Elementary schools principals, high schools principals and school superintendents spend 70 to $80 \%$ of their time in communication (Lunenburg \& Irby, 1994). Administrators spend $80 \%$ of their time in communication.

\footnotetext{
${ }^{1}$ Assistant Professor, Institute of Education \& Research, University of Science \& Technology Bannu, Pakistan Email: rahmatullahshah@gmail.com
} 
Communication is essential for the business of an institution (Mintzberg, 1997).An institution cannot be managed without proper communication. Open communication makes the work of an educational manager more effective within a school. Open communication makes the school more effective, while poor communication results in ineffective control, poor coordination and inevitable management failure (Arshad, 2003). For the implementation of an information system, it is necessary that the right people must communicate the right information, at the right time and through the right media (Bakehouse \& Doyle, 2007). Three variables work as predictors of members' communication satisfaction. These variables include easy use of communication medium, participation and decision confidence (Olaniran, 1996).

Leadership styles of an educational manager may affect communication within an institution. Supervisor task and relational leadership style are strongly related to supervisor' communication competence (Madlock, 2008). Strong correlation exists among perceived communication variables, i.e., the quality of supervisory communication and information exchange within peer work groups, and critical revenue and workload measures of overall organization performance (Snyder \& Morris, 1984).

\section{$1.1 \quad$ Objectives of Study}

Following were objectives of the study:

1. To compare academic department heads' perceptions by academic qualification regarding their role in promotion of communication in universities.

2. To compare academic department heads' perceptions by age regarding their role in promotion of communication in universities.

3. To compare academic department heads' perceptions by length of service regarding their role in promotion of communication in universities.

4. To compare academic department heads' perceptions by experience as chair regarding their role in promotion of communication in universities.

\subsection{Hypotheses of Study}

$\mathrm{H}_{01}$ There is no significant difference among the views of heads of teaching departments by qualification regarding their role in the promotion of communication in universities.

$\mathrm{H}_{02}$ There is no significant difference among the opinions of heads by age regarding their role in the promotion of communication.

$\mathrm{H}_{03}$ There is no significant difference among the views of heads by experience regarding their role in the promotion of communication. 
$\mathrm{H}_{04}$ There is no significant difference among the opinions of heads by experience as chair about their role in the promotion of communication.

\subsection{Significance of Study}

This study will be useful not only for teaching department heads but for teachers also. The study will prove a useful document for authorities of a university. The study will work as a guide for policy makers. Students and parents will be beneficiaries of this study. This study will open new area of research for further researches.

\section{Literature Review}

Communication is essential for the administration of an institution. "Not only do administrators spend much of their time in talking and that this talk accomplishes administration, but that talk is used to do the work of tightening and loosening administrative control" (Gronn, 1983).To get work done by employees, their job satisfaction should be increased. Effective communication enhances job satisfaction of the employees. Strong relationship exists between communication climate and job satisfaction of academic department chairs, and the communication climate activities are characterized by mutual influence, openness and free flow of information (Alexander, 1996). To make exchange of information more effective, a competent person must be made in charge for the management of information on the campus. The appointment of a competent person as a communicator will be helpful in the accomplishment of organizational goals. Positive and significant association exists between communication abilities and attainment of organizational rewards (Zorn \& Violant, 1996).

Heads and teachers exchange information with each other, but how to make this sharing an effective one, is an important matter. Effective communication between heads and teachers results in organizational commitment. However, lack of communication between heads and teachers negatively affects organizational commitment. Less perceived freedom of speech in the workplace results in less employees' organizational commitment and satisfaction with their work and supervisor. Employees wish more freedom of speech in the workplace than they presently have (Gorden \& Infante, 1991). The head of teaching department communicates in three directions, i.e. downward, upward, and horizontal. These directions of communication affect level of commitment of employees within the institution. Strong relationship exists between vertical communication and the levels of commitment at both organizational and unit level as compare to horizontal communication (Postmes, 2001). The perceptions of employees also affect credibility of information within 
an organization. Positive relationship exists between effective internal communication and perceptions of employees in the firm. Effective communication among employees increases not only their commitment, but also enhances the output of an organization (Unzicker, Clow \& Babakus, 2000).

Sometimes communication barriers emerge which halt the process of communication within an organization. These communication barriers negatively affect the output of an organization. For the avoidance or elimination of these barriers, trust among employees is essential. Transparency in information sharing is necessary for the development of trust among employees. An atmosphere of trust can eliminate or minimize communication barriers, i.e. context-related barriers and content-related barriers within an organization (Phelps \& Dufrene, 1989). Dynamic relationships and interactions are responsible for downward and upward distortions, and the organizational climate (Athanassiades, 1973). Effective communication not only develops trust but may also be helpful in the incorporation of innovations. As world has become a global village, innovations are taking place very rapidly in every organization, especially in the institutions of higher education. A university not only transmits knowledge, but also generates it. These innovations may take place in academic structure, i.e. admission policy, curriculum development, methods of teaching, system of examination and management structure, i.e. planning, organizing, staffing, directing, reporting and budgeting of an educational institution. Proper exchange of information between heads and teachers is helpful in incorporation of these innovations. Communication variables i.e. level of information and group communication are the causes of organizational innovation (Monge, Cozzens \& Contractor, 1992).

Communication variables: quality of communication, interpersonal communication and mediated communication has both direct and indirect effects on perceived innovativeness. Mediated channels play a critical role in the implementation of management-initiated innovations (Johnson et al, 2001).

The head plays a very important role in the management of a teaching department. The head is an essential link between the faculty and administration. He plays his role as a manager as well as a faculty member. The head spends most of his time in managerial duties. Majority of heads work more than 50 hours per week, and that dealing with under-performing staff is the most difficult issue as indicated by the heads in both chartered and statutory universities (Smith, 2002). The academic head is busy in most of the time in managerial tasks, does many works at a time, interact with many people at a time, and as a result he becomes stressed. The chairs feel much stress because of heavy workload, and the stressors include time pressures, confrontation with colleagues, 
organizational constraints and their faculty duties. They (chairs) are in paradoxical situation: experiencing double pressures as an effective leader and as a productive faculty member (Gmelch \& Burns, 1994). They pointed out that chairs felt high stressed in both areas of faculty and administration. As nobody has explored the role of heads of academic departments in the promotion of communication in the institutions of higher education in Pakistan, the researcher decided to make comparison among views of heads of teaching departments by qualification, age, total experience and experience as chairs regarding their role in the promotion of communication in the institutions of higher education in Pakistan.

\subsection{Research Design}

\section{Research Methodology}

The study was descriptive in nature. Survey method design was used for the study.

\subsection{Population and Sample}

The population of the study consisted of all heads of teaching departments of public sector universities in Khyber Pakhtunkhwa, Pakistan. The sample of the study consisted of all heads of eight selected universities in Khyber Pakhtunkhwa, Pakistan. All heads of the teaching departments of the selected universities were included as respondents of the study. The sample consisted of 124 respondents.

\subsection{Research Instrument}

A two-part questionnaire was administered by the researcher to the subjects Part- 1 of the questionnaire consisted of eight independent variables as demographic characteristics viz Type of institute, Name of teaching department, designation, age, gender, qualification, total length of service in the present department and experience as chairperson.

Part- II of the questionnaire consisted of 27 Likert-type items, responded on a 5 point scale from "Always to Never", carrying a value of 5 to 1 respectively. Items designated positively are scored by 5, 4, 3, $2 \& 1$ respectively. Items designated negatively are scored in the reverse manner. Omitted or invalid responses are given a score of 3 . The questionnaire was developed by the researcher himself. Twenty-seven items of the questionnaire reflect the communicative behaviors of a head of teaching department which make his/her role as a communicator. 


\subsection{Validity \& Reliability}

The content validity of the scale was checked by the researcher' $\mathrm{Ph} . \mathrm{D}$ research supervisor and experts in social sciences. For the purpose of reliability of the scale, a random sample of 60 respondents was selected. This number was excluded from the final sample. Cronbach's coefficient Alpha formula was used in estimating the internal consistency of the scale. Obtained Cronbach's Alpha was 0.937 for the scale. In general the reliabilities less than 0.6 are considered to be poor, those in the 0.70 range are acceptable, and those over 0.8 are considered good (Sekaran, 1999). George and Mallery (2003) gave these rules of thumb: " $\geq .9$ =Excellent, $\geq .8=$ Good, $\geq .7=$ Acceptable, $\geq .6=$ Questionable, $\geq .5=$ Poor, and $\leq .5$ = Unacceptable" (cited in Gliem \& Gliem, 2003). The scale was developed by the researcher, so its Cronbach's Alpha could not be compared to any other scale in the literature.

\subsection{Data Collection} respondents.

Researcher personally administered the questionnaire from the

\section{Data Analysis \& Results}

One-Way ANOVA was used to find out Means difference among opinions of heads by experience as a chair, age, qualification and total length of experience in the present department. The SPSS statistical software package, version 16.0, was used to analyze the quantitative data.

Table 1

Comparison among the views of heads by qualification

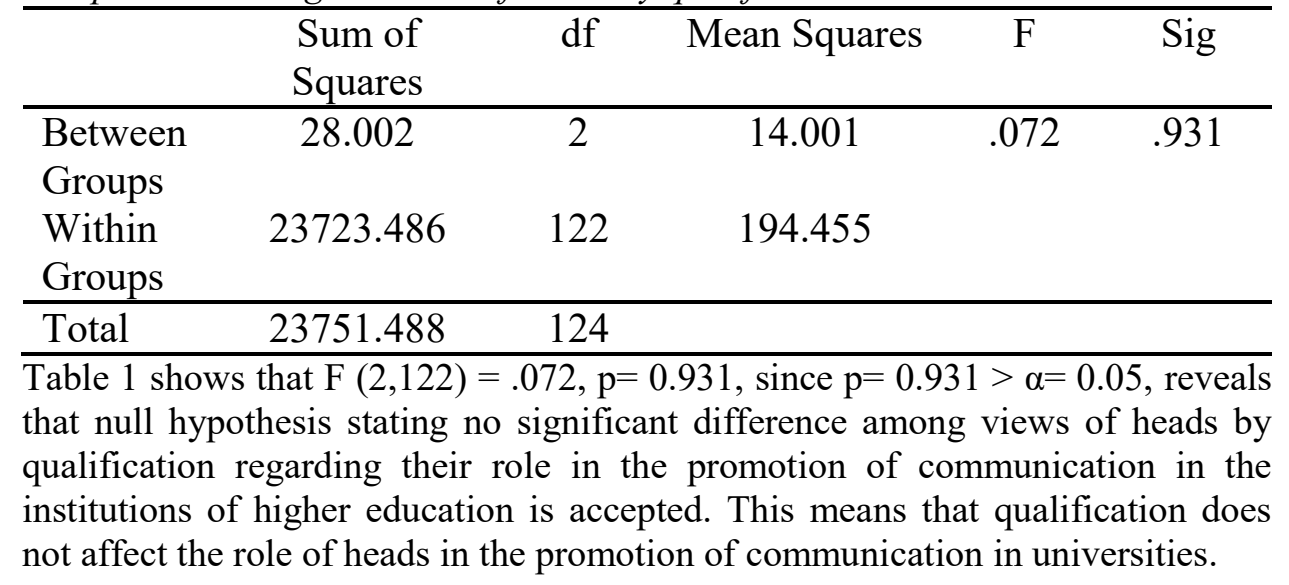


Table 2 Comparison among the opinions of heads by age

\begin{tabular}{lccccc}
\hline & $\begin{array}{c}\text { Sum of } \\
\text { Squares }\end{array}$ & df & $\begin{array}{c}\text { Mean } \\
\text { Squares }\end{array}$ & F & Sig \\
\hline Between & 517.455 & 2 & 190.443 & 1.359 & .261 \\
$\begin{array}{l}\text { Groups } \\
\text { Within }\end{array}$ & 23234.033 & 122 & 258.727 & & \\
Groups & & & & & \\
\hline Total & 23751.488 & 124 & & \\
\hline
\end{tabular}

The hypothesis 2 is that there is no significant difference among the views of heads by age regarding their role in the promotion of communication in universities. Results showed that $\mathrm{F}(2,122)=1.359, \mathrm{p}=.261$, since $\mathrm{p}$-value $=.261$ $>.05$, so null hypothesis is accepted.

Table 3

Comparison among views of heads by total length of experience

\begin{tabular}{lccccc}
\hline & $\begin{array}{c}\text { Sum of } \\
\text { Squares }\end{array}$ & df & Mean Squares & F & Sig \\
\hline $\begin{array}{l}\text { Between } \\
\text { Groups }\end{array}$ & 869.149 & 3 & 289.716 & 1.532 & .210 \\
$\begin{array}{l}\text { Within } \\
\text { Groups }\end{array}$ & 22882.339 & 121 & 189.110 & & \\
\hline Total & 23751.488 & 124 & & & \\
\hline
\end{tabular}

Hypothesis 3 was that there was no significant difference among the opinions of heads by total university experience regarding their role in the promotion of communication. Table 4.3 reflects that $\mathrm{F}(3,121)=1.532, \mathrm{p}=.21, \mathrm{p}=.21 \geq 0.05$, so null hypothesis is accepted. This means that heads of different experiences have similar opinions regarding their role in the enhancement of communication in universities.

Table 4

Comparison among views of heads by experience as chair

\begin{tabular}{lccccc}
\hline & $\begin{array}{c}\text { Sum of } \\
\text { Squares }\end{array}$ & df & Mean Squares & F & Sig \\
\hline $\begin{array}{l}\text { Between } \\
\text { Groups }\end{array}$ & 18.064 & 2 & 9.032 & 15.700 & .000 \\
$\begin{array}{l}\text { Within } \\
\text { Groups }\end{array}$ & 69.613 & 121 & .575 & & \\
\hline Total & 87.677 & 123 & & & \\
\hline
\end{tabular}


Hypothesis 4 was that there was no significant difference among the opinions of heads by experience as chairman of the teaching department regarding their role in the promotion of communication. Table 4.4 shows that $F(2,121)=15.7$, since $\mathrm{p}$-value $=.000 \leq 0.05$ so null is rejected. The null hypothesis is that there is no significant difference among the opinions of heads by experience as chair. This means that chairpersons of different experiences have different communicative behaviors in their role as a communicator.

\section{Findings \& Discussion}

The first objective of the study was to compare the views of heads by qualification regarding their role in the promotion of communication in institutions of higher education. Qualification wise heads were placed into three categories, i.e. Ph.D, M.Phil and Master. Minimum qualification for the appointment of a head of teaching department is Master Degree. They are promoted on the basis of experience, academic qualification and performance. The result showed no significant difference among the views of heads by academic qualification. This implies that academic qualification of the heads do not affect their role as a communicator. The reasons of insignificant difference among the views of heads of teaching departments may be that they have equal access to communication channels. They are fairly provided with equal professional development opportunities. They have opportunities to develop themselves as a good communicator.

$2^{\text {nd }}$ and $3^{\text {rd }}$ objective of the study were to know difference among the views of heads by age and total experience. No significant difference was observed among opinions of heads by age and total length of experience regarding their role in the promotion of communication in universities. This means that age and total experience of heads do not affect their role in the promotion of communication. This does not confirm the study of Zenger and Lawrence (1989). They found relationship of age and tenure distribution with frequency of technical communication. Young workers experience more difficulty in communication with old workers as compared to their same age workers (McCann \& Giles, 2007). People of different ages communicate differently (McCann et al, 2005). This means that age determines the patterns of communication. Minimum age is 18 years for the appointment of a government servant and 60 years for retirement in Pakistan. The same rule of age is applied to both heads and teachers. After retirement, a Ph.D degree holder can serve for the period of five years on contract basis in a university.

The $4^{\text {th }}$ objective of the study was to explore difference in the views of heads by experience as a chair. There was significant difference among the views of heads by experience as chair regarding their role in the promotion of 
communication. This means that heads with experience as a chair have different perceptions about their role in the promotion of communication in universities. The reasons of this significant difference may be the following:-

1. They have unequal access to communication channels.

2. High-ups do not provide them with desired information.

3. They are not properly trained as a communicator.

4. Subordinates do not properly share information with them

\section{Conclusion}

The chairmanship experience of university teaching department heads affect their views regarding their role in the promotion of communication on the campus. Qualifications of the chairmen of teaching departments do not prove to be a strong variable in producing significant change in their opinions regarding their role in the promotion of communication in universities. Total experiences of academic department heads do not affect their views regarding their role in the promotion of communication. Age of the academic heads does not differentiate them in their perceptions about communication practices on the campus.

\section{Recommendations}

Following recommendations were offered:-

1. To make a head of department an effective communicator, training in communication skills may be given to them. For this purpose, a communication training institute may be established where heads of teaching departments may be trained.

2. The head of department plays his/her role as a leader, manager and administrator. For the performance of this multifaceted job, it is essential for the head of teaching department to be a good communicator. For this purpose, a reorientation course of communication skills may be recommended for the newly inducted heads.

3. Language, the basic tool of communication, is used for the transmission of both verbal and written messages within an organization. Urdu is the national and English is the official language of Pakistan. These languages are also used as a medium of instruction in educational institutions. As English is an official language of Pakistan, therefore, all official correspondence is done in English. For the improvement of language proficiency of the heads and teachers, a language laboratory may be established in every university.

4. Teaching department is a teaching as well as an administrative unit of a university or postgraduate college. Various educational activities take place within a department daily. For the better projection of these activities, every teaching department may publish its own newsletter on monthly basis. 
5. Internet is the fast and cheap mode of communication today. The users of Internet are increasing day by day in Pakistan. Every university has developed its own website. All relevant information about the institute is available on its website. This is usually observed that website is overloaded of information. Sometimes very important information does not find place in the website. For the better accommodation of relevant information, every teaching department may develop its own website. The website may be updated regularly.

\section{References}

Alexander, K. E. (1996). The relationship between communication climate and job satisfaction of Florida' community college department chairs $(\mathrm{PhD}$ Dissertation).University of Florida, USA.

Arshad, M. (2003). A study of organizational culture and effectiveness of secondary school (PhD dissertation).University of the Punjab, Pakistan.

Athanassiades, J. C (1973). The sounds and silences of employee communication. Journal of Business Communication, 10(4), 43-50.

Bakehouse, G., \& Doyle, K (2007 Feb 2). Commitment, co-ordination and communication. Retrieved from hptt://www.accagloabal.com/students/study_exams/qualifications/acca.

Gliem, J. A., \& Gliem, R. R (2003). Calculating, interpreting and reporting Cronbach's alpha reliability coefficient for Likert type scales. Paper presented at 2003 Midwest Research to Practice Conference in Adult, Continuing, and Community Education.

Gmelch, W. H., \& Burns, J. S. (1994). Sources of stress for academic department chairpersons. Educational Administration, 32(1), 79-94.

Gronn, P. C. (1983). Talk as the Work: The Accomplishment of School Administration. Administrative Science Quarterly, 28(1), 1-21.

Johnson, J. D., Donohue, W. A., Atkin, C. K. \& Johnson, S (2001). Communication, involvement, and perceived innovativeness: Tests of a model with two contrasting innovations. Group and Organization Management, 26(1), 24-52.

Gorden, W.I., \& Infante, D. A. (1991). Test of a communication model of organizational commitment. Communication Quarterly, 39(2), 144-155. 
Lunenburg. F. C.,\& Irby. B. U (1994). Principalship vision to action. Belmont. CA. Wordsworth Thomson Learning in Press.

Madlock, P. E (2008).The Link between Leadership Style, Communicator Competence, and Employee Satisfaction. International Journal of Business Communication. 45(1), 61-78.

McCann, M. R.,\& Giles, H. (2007). Age-differentiated communication in organizations: Perspectives from Thailand and the United States. Communication Research Reports, 24(1), 106-112.

McCann, M. R., Dailey, M. R., Giles, H., \& Ota, H. (2005). Beliefs about intergenerational communication across the life span: Middle age and the roles of age stereotyping and respect norms. Communication Studies 56(4), 293-311.

Mintzberg, H (1997). The nature of managerial work. Reading, MA: AdisonWesley.

Olaniran, B. A (1996). A model of group satisfaction in computer-mediated communication and face-to-face meetings. Behavior and Information Technology, 15(1), 24-36.

Monge, P., Cozzens, M., \& Contractor, N. (1992). Communication and Motivational Predictors of the Dynamics of Organizational Innovation. Organization Science, 3(2), 250-274. doi: 10.1287/orsc.3.2.250

Phelps, L. D., \& Dufrene, D. D (1989). Improving organizational communication through trust. Journal of Technical Writing and Communication, 19(3), 267-276.

Postmes, T., Tanis, M., \& De Wit, B. (2001). Communication and commitment in organizations: A social identity approach. Group Processes and Intergroup Relations, 4(3), 227-246.

Sekaran, U (1999). Research methods for business: A skill building approach. Southern III notes, University of Carbondale.

Smith, R (2002). The role of the university head of department. Educational Management, Administration and Leadership, 30(3), 293-313.

Snyder, R. A., \&Morris, J. H. (1984). Organization communication and performance. Journal of Applied psychology, 69(3), 461-465. 
Unzicker, D,. Clow, K. E., \& Babakus, E (2000). The role of organizational communication on employee perceptions of a firm. Journal of Professional Services Marketing, 21(2), 87-103.

Zenger, T. R., \& Lawrence, B. S. (1989). Organizational demography: The differential effects of age and tenure distributions on technical communication. The Academy of Management Journal, 32(2), 353-376.

Zorn, T. E., \& Violant, M. T (1996). Communication abilities and individual achievement in organizations. Management Communication Quarterly, 10(2), 139-167. 